\title{
Cytological and cultural evaluation of abnormal vaginal discharge in pregnancy and its co-relation with maternal and neonatal outcome
}

\author{
Vaibhav Suresh Khairnar*, Manjushri Ravi Waikar
}

Department of Obstetrics and Gynecology, Indira Gandhi Government Medical College, Nagpur, Maharashtra, India

Received: 11 December 2019

Accepted: 04 January 2020

\section{*Correspondence:}

Dr. Vaibhav Suresh Khairnar,

E-mail: vaibhav.bjmc@gmail.com

Copyright: () the author(s), publisher and licensee Medip Academy. This is an open-access article distributed under the terms of the Creative Commons Attribution Non-Commercial License, which permits unrestricted non-commercial use, distribution, and reproduction in any medium, provided the original work is properly cited.

\section{ABSTRACT}

Background: Pregnancy represents a risk factor in the occurrence of vaginal infection. This study was undertaken to define the persistence of vaginal flora in 280 pregnant women at 14 to 34 weeks' gestation and to evaluate the role of cytology in diagnosis of vaginal infections. It aims to study the maternal and neonatal outcome in pregnancy with vaginal discharge.

Methods: High vaginal swab samples and data on epidemiological characteristics were collected from 280 pregnant women between 14-34 weeks with complaints of abnormal vaginal discharge at booking clinic of Indira Gandhi Government Medical College, Nagpur. Vaginal swab was collected and sent to laboratory for further investigation to establish etiological diagnosis. After diagnosis by vaginal swab report, subjects were treated with the specific treatment to individual infection. Subjects were followed up during antenatal period for complications. A birth weight of delivered baby was noted. The data was analysed using software Graph Pad in stat 3.

Results: The incidence of abnormal vaginal discharge in pregnancy was $23.9 \%$ in one year. The frequency of abnormal discharge was 53\% among those aged 20-24 years (97/183), 49.2\% in primigravida (65/132). Pain in lower abdomen and back was the most common symptoms i.e. $88.19 \%$ in Cases, while $17.36 \%$ had vulval pruritus and $14.58 \%$ had dysuria.

Conclusions: This study recommend that women complaining of vaginal discharge in pregnancy should be evaluated for infections. this study supports CDC-P recommendation as all women who have symptomatic vaginitis, should be treated regardless of pregnancy status.

Keywords: Bacterial vaginosis, Candidiasis, Cytology, Trichomoniasis, Vaginal discharge

\section{INTRODUCTION}

Vaginal discharge is common condition which affects many women during their reproductive years. Because of its relatively trivial nature, vaginal discharge is often not investigated fully and empirical treatment may be initiated based on clinical finding alone. The incidence of vaginal discharge rises during pregnancy. ${ }^{1}$ In Pregnancy the normal flora of the vagina changes according to circulating oestrogen levels. When oestrogen is present, the vaginal epithelium contains glycogen which favours colonization of lactobacilli and other acid tolerant bacteria which metabolise glycogen to lactic acid. This results in a $\mathrm{pH}$ of 4.5 or less. Other common commensals which can act as pathogens includes Candida species, Staphylococci and Beta-haemolytic Streptococci including Streptococcus agalactiae and Actinomyces species.

Another common condition is bacterial vaginosis, a synergistic interaction between obligate anaerobes and Gardnerella vaginalis. ${ }^{2}$ Trichomonas vaginalis is a less 
frequent cause of vaginal discharge but remains important because it is transmitted by sexual contact. In Bacterial vaginosis, the concentration of Gardnerella vaginalis, Mobiluncus species, Mycoplasma hominis and Anaerobic Gram-negative rods like Bacterioides species, Prevotella species, and Porphyromonas species increases compared with the lactobacilli. However, the common etiological agents of vaginal discharge respond to specific therapies and their symptoms are sufficiently similar to render clinical diagnosis difficult. Therefore, laboratory investigations are appropriate. Psychosexual problems and depression can present with recurrent episodes of vaginal discharge. These need to be considered if tests for specific infections are negative. ${ }^{3}$ Adverse vaginal flora is associated with spontaneous preterm labour. Bacterial vaginosis has been associated with spontaneous abortion, preterm labour, premature rupture of membranes, chorioamnionitis, amniotic fluid infection and low birth weight new-borns. ${ }^{4}$

This study was undertaken with the objective to ascertain the incidence of abnormal vaginal discharge in pregnancy between 14-34 weeks in our institute and risk factors associated with increased vaginal discharge in pregnancy, to evaluate role of cytology in diagnosis of vaginal infections and to analyse the maternal and neonatal outcome in pregnant women with vaginal discharge.

\section{METHODS}

\section{Study design and participants}

It was hospital based observational study conducted from December 2011 to October 2013 over a period of one year 10 months at Indira Gandhi Government Medical College, Nagpur on 280 pregnant women with 144 cases and 136 controls. The main inclusion criteria for cases was those pregnant women with vaginal discharge and for controls was pregnant women with no complaint of vaginal discharge in gestation age between 14-34 weeks. Women with any of the following criteria were excluded from study: Pregnant women in active labour; pregnant women with vaginal bleeding; PROM (premature rupture of membranes); pregnant women with Cervical Encerclage done.

\section{Data collection}

All participants gave informed consent which was approved by the local ethics committee. History was taken in details about presenting symptoms like vaginal discharge, its character, colour, associated symptoms like pain in abdomen and back, dysuria and itching. Additional risk factors like low socioeconomic status (ration card showing below poverty line), past history of diabetes mellitus, immune compromised status was enquired. General examination, obstetrical examination, local examination of genital area and per speculum examination done under asepsis. The presence and colour of discharge, signs of inflammation over vulva, vagina and cervix were noted and vaginal swab was collected during speculum examination from posterior and lateral fornices and sent to laboratory for wet smear and mount, Gram's staining and culture investigation to establish etiological diagnosis as early as possible.

\section{Outcome measures}

Candidiasis was detected clinically by the presence of curdy white discharge and in the laboratory by Gram's stain, $\mathrm{KOH}$ mount and culture on Sabouraud's agar from a swab taken from the posterior fornix. Trichomoniasis (TV) was suspected by the presence of green yellow frothy discharge and strawberry vagina on clinical examination and diagnosed with wet mount and culture of discharge on Kupferberg's medium. Bacterial vaginosis (BV) was identified by the presence of a homogeneous white vaginal discharge. Gram-stained smears are evaluated for their morphotypes. Culture for Bacterial vaginosis was not done as it was not sensitive method. Nugent score was used for diagnosis of Bacterial vaginosis (Table 1 ).

Table 1: Nugent score for bacterial vaginosis.

\begin{tabular}{|c|c|c|c|}
\hline \multirow[b]{2}{*}{ Score } & Organism & \multicolumn{2}{|l|}{ Morphotype per high power field } \\
\hline & $\begin{array}{l}\text { Lactobacilli (parallel - } \\
\text { sided, gram positive rods) }\end{array}$ & $\begin{array}{l}\text { Gardnerella/Bacterioids tiny, gram variable } \\
\text { cocco-bacilli and rounded, pleomorphic, gram } \\
\text { negative rods with vacuoles }\end{array}$ & $\begin{array}{l}\text { Mobilungus (curved } \\
\text { gram-negative rods) }\end{array}$ \\
\hline 0 & $>30$ & 0 & 0 \\
\hline 1 & $5-30$ & $<1$ & $1-5$ \\
\hline 2 & $1-4$ & $1-4$ & $>5$ \\
\hline 3 & $<1$ & $5-30$ & - \\
\hline 4 & 0 & $>30$ & - \\
\hline
\end{tabular}

\section{Diagnosing criteria}

normal (0-3), intermediate (4-6), positive (7-10).
After confirmed diagnosis by swab report, subjects were treated accordingly. In our study, subjects were followed up during antenatal period for complications like $\mathrm{PIH}$, UTI, GDM and IUFD till delivery and outcome seen as 
FTND, FTCS and PTND. A birth weight of each delivered baby was noted. We also look for incidence of PROM in all delivered subjects. Subjects were followed up in post-partum period as well for complications like in puerperal sepsis, puerperal pyrexia, neonatal sepsis and adherent placenta.

\section{Statistical analysis}

We used the chi-square test to compare discrete values between two groups. A P-value less than 0.05 were considered significant. Fischer exact test was also used. Statistical analyses were done by using software graphpad in stat 3 .

\section{RESULTS}

In the present study, the total no of pregnant women registered in antenatal OPD in one-year 2012 were 4025, out of that 961 subjects presented with the complaint of vaginal discharge. Incidence was $23.9 \%$. Out of this, 144 subjects selected at random and compared with 136 controls without vaginal discharge.

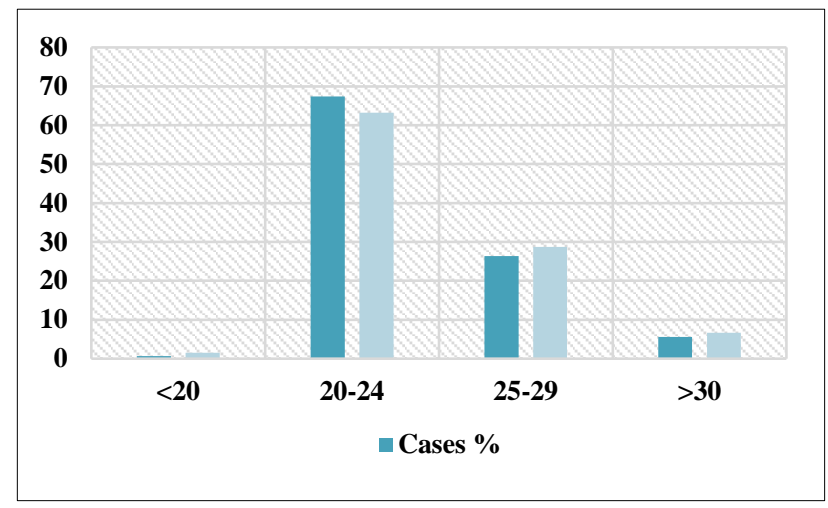

Figure 1: Distribution of subjects according to age.

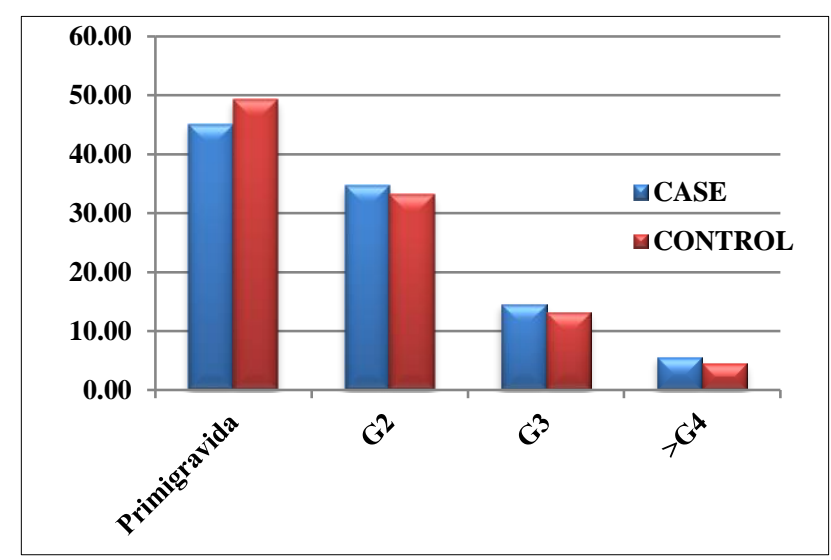

Figure 2: Distribution according to gravid status of subjects.

In both groups, most of the subjects were in the age group of 20-24 years i.e. $67.36 \%$ in cases and $63.24 \%$ in controls. $26.39 \%$ in cases and $28.68 \%$ in controls were in age group of 25-29 years. The mean age in cases and control groups was 23.71 \pm 3.31 and 23.85 \pm 3.11 respectively which was comparable (Figure 1).

In our study, majority of subjects in both groups were primigravida, $45.14 \%$ in cases and $49.26 \%$ in Controls, while $34.72 \%$ in cases and $33.09 \%$ in controls were second gravida, hence both the groups were comparable (Figure 2).

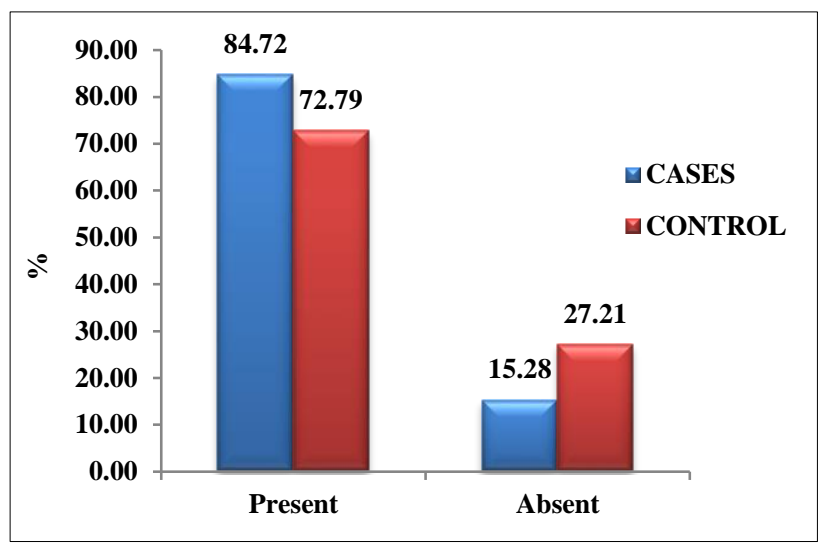

Figure 3: Distribution according to presence of social risk factors.

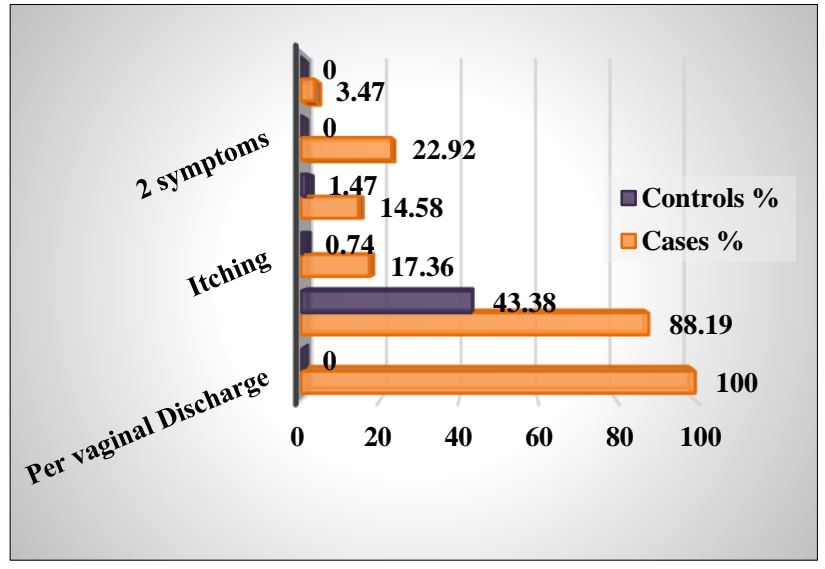

Figure 4: Distribution according to the presenting symptoms.

As seen in this chart, $84.72 \%$ from cases were from lower socio-economic class while only $72.79 \%$ from controls were from lower socio-economic class, hence women in cases group were from lower socioeconomic class had vaginal discharge as complaint as compared to women in control group (Figure 3). In study, we found only 2 cases were HIV positive who were from low socio-economic status, while none of the other subjects had any associated medical risk factor.

According to the presence of associated symptoms apart from $\mathrm{p} / \mathrm{v}$ discharge, pain in lower abdomen and back was the most common symptoms i.e. $88.19 \%$ in cases, while $17.36 \%$ had itching and $14.58 \%$ had dysuria. Cases with any 2 symptoms among pain in abdomen, itching and 
dysuria were $22.92 \%$, while $3.47 \%$ had 3 associated symptoms. We found that milky white per vaginal discharge was common in 139 cases i.e. 96.53\% (Figure 4). Candida was grown in 21 cases of milky white discharge i.e. $15.11 \%$. Candida was grown in culture in all cases with curdy white discharge i.e.100\%. Trichomoniasis was grown in 1 case of greenish vaginal discharge.

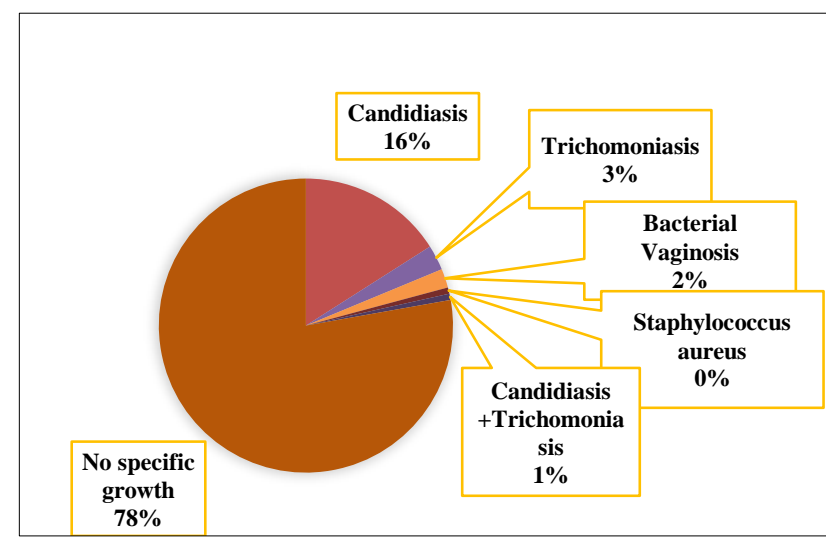

Figure 5: Distribution according to vaginal swab gram's staining and culture report.

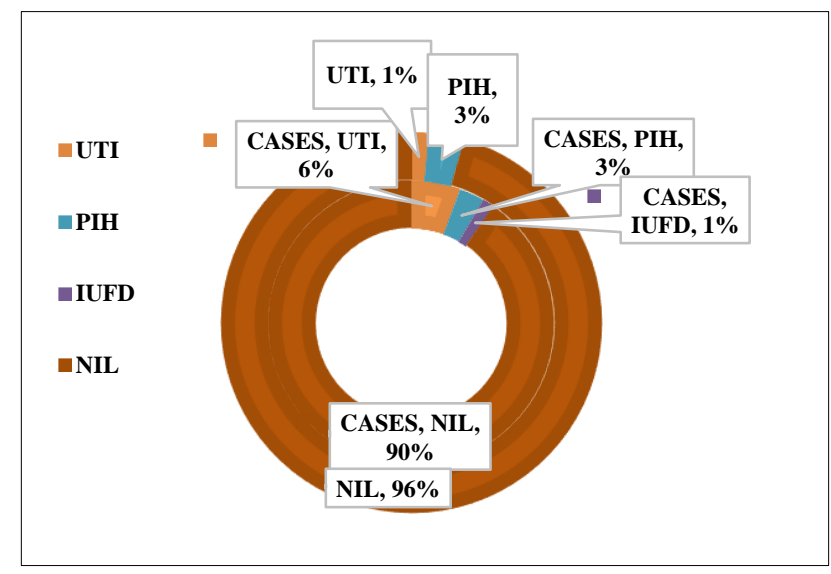

Figure 6: Distribution according to complications during pregnancy.

We found no specific growth in $77.77 \%$, Candidiasis in $15.97 \%$, trichomoniasis in $2.77 \%$, Bacterial vaginosis in $2.08 \%$, staph aureus in $0.69 \%$ on swab and culture report. While according to clinical suspicion, Candidiasis was most common among positive finding among cases i.e. $74.19 \%$, Trichomoniasis was next common finding i.e.12.9\%. Followed by Bacterial vaginosis $9.6 \%$, only 1 subject had mixed vaginitis i.e. $0.14 \%$ (Figure 5).

In our study, UTI was seen in 8 subjects among cases i.e. $5.56 \%$ and 2 subjects in controls. Out of 8 subjects of UTI, 5 subjects were associated with no specific growth, 1 with Candidiasis, 1 with Bacterial vaginosis and 1 with Trichomoniasis. PIH was seen as associated in 4 subjects in cases as well as control. Out of 39 delivered subjects from cases group $2(5.13 \%)$ had PROM, out of these 2 subjects 1 had PTND, while none in control had PROM. $\mathrm{P}$-value according to Fischer exact test was 0.4935 ( $\mathrm{P}>$ $0.05)$, hence the difference in incidence of PROM in cases and control was statistically not significant (Figure $6)$.

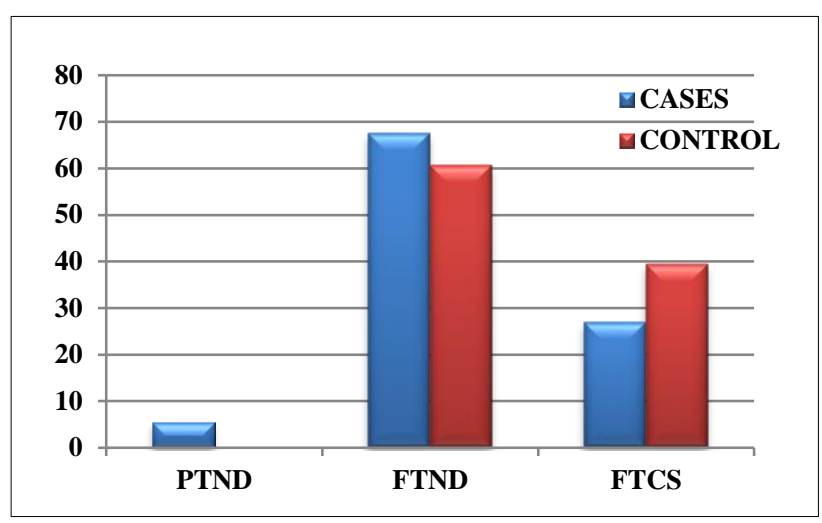

Figure 7: Mode of delivery.

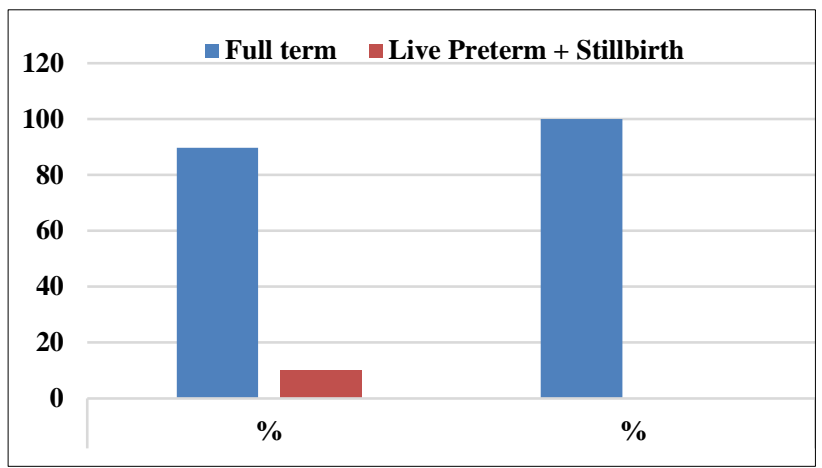

Figure 8: Delivery outcome.

In our study, out of 280 subjects, 77 delivered in our institute during study period, out of 37 from cases group $25(67.56 \%)$ had FTND, $10(27.02 \%)$ had FTCS and 2 $(5.40 \%)$ delivered as PTND while out of 38 from control group $23(60.52 \%)$ had FTND and $15(39.47 \%)$ delivered by FTCS (Figure 7).

According to neonatal outcome, out of 77 subjects delivered in our institute, $4(10.26 \%)$ from cases had preterm, from the 4 preterm $2(5.12 \%)$ subjects had delivered stillbirth, $35(89.74 \%)$ and 38 (100\%) from cases and control group respectively delivered full term babies (Figure 8).

\section{DISCUSSION}

Vaginal secretion is mainly derived from the glands of the cervix, uterus, transudation of vaginal epithelium and bartholin's glands as well as exfoliated epithelial cells, bacteria and bacterial products. Vaginal discharge is a common presenting symptom seen by doctors in many services (primary care, gynaecology, family planning, and departments of genitourinary medicine). Vaginal discharge may be physiological or pathological. ${ }^{5}$ This 
article focuses on the cytological and culture evaluation of abnormal vaginal discharge in pregnancy and its corelation with maternal and neonatal outcome.

Recent advances are changing investigation techniques and the management of vaginal discharge. Clinicians need to be aware of emerging epidemiological data, the different presentations of vaginal discharge, and how to approach their management so that the symptom can be treated according to its aetiology.

\section{Causes of vaginal discharge}

- Non-infective
a. Physiological
b. Cervical ectopy
c. Foreign bodies, such as retained tampon
d. Vulval dermatitis.

- Non-sexually transmitted infection
a. Bacterial vaginosis
b. Candida infections.

- Sexually transmitted infection

a. Chlamydia trachomatis

b. Neisseria gonorrhoeae

c. Trichomonas vaginalis.

Many link bacterial vaginosis directly to a number of serious obstetrical complications like spontaneous abortion, preterm labour, preterm premature rupture of membranes, preterm birth, amniotic fluid infection, postpartum endometritis, post caesarean wound infection. ${ }^{6}$

In our study most of the subjects were primigravida and most of them were in the age group of 20-24 years. This was because of early marriage at 19-20 years in our country and women conceive in 1-2 years after marriage.

The difference in the incidence of vaginitis in women from lower socio-economic class and women from middle class was statistically significant (as $p<0.05$ ). In study done by Ibrahim SM et al, it was found that $73.2 \%$ cases were from lower socio-economic class and is comparable with our study. ${ }^{7}$ In study done by Shrestha $S$ et al, vaginitis was highest in illiterate women from lower socio-economic class. ${ }^{8}$

As seen in Table 2, we found that per vaginal discharge in $51.43 \%$ (144) of the total observed subjects, which was comparable with $69.9 \%$ in the study done by Elizabeth et al. ${ }^{9}$ Itching was seen in $9.29 \%$ (26) of cases and was comparable with $8 \%$ found in the study done by Romoren $\mathrm{M}$ et al. ${ }^{10}$ All subjects of Bacterial vaginosis and Trichomoniasis, presented with $\mathrm{p} / \mathrm{v}$ discharge. However, itching was not as a common symptom with BV but with Trichomoniasis, itching was complained by $50 \%$ and dysuria was seen in association with pain and itching in $25 \%$ of cases (Table 2 ).

Table 2: Comparison of presenting symptoms in different studies.

\begin{tabular}{|c|c|c|c|}
\hline Presenting symptom & Romoren $\mathrm{M}$ et $\mathrm{al}^{10}(\%)$ & Elizabeth et al ${ }^{9}(\%)$ & Present study (2011-13) (\%) \\
\hline Per vaginal discharge & 17 & 69.9 & 51.43 \\
\hline Pain in abdomen and back & 8 & - & 66.43 \\
\hline Itching & 8 & - & 9.29 \\
\hline Dysuria & 1 & - & 8.21 \\
\hline Bad odour & 0 & 28.7 & 0 \\
\hline Dyspareunia & 0 & 29.4 & 0 \\
\hline
\end{tabular}

Table 3: Distribution of cases according to clinical looks of the per vaginal discharge.

\begin{tabular}{|c|c|c|c|c|c|c|c|c|c|c|c|c|}
\hline \multirow{2}{*}{$\begin{array}{l}\text { Colour of } \\
\text { discharge }\end{array}$} & \multicolumn{2}{|c|}{ Candidiasis } & \multicolumn{2}{|c|}{ Bacterial vaginosis } & \multicolumn{2}{|c|}{ Trichomoniasis } & \multicolumn{2}{|c|}{ No specific growth } & \multicolumn{2}{|c|}{ Others } & \multicolumn{2}{|c|}{ Total } \\
\hline & No & $\%$ & No & $\%$ & No & $\%$ & No & $\%$ & No & $\%$ & No & $\%$ \\
\hline Milky white & 21 & 15.11 & 3 & 2.16 & 3 & 2.16 & 110 & 79.14 & 2 & 1.44 & 139 & 96.53 \\
\hline Curdy white & 2 & 100 & 0 & 0 & 0 & 0 & 0 & 0 & 0 & 0 & 2 & 1.39 \\
\hline Greenish & 0 & 0 & 0 & 0 & 1 & 100 & 0 & 0 & 0 & 0 & 1 & 0.69 \\
\hline Altered brown & 0 & 0 & 0 & 0 & 0 & 0 & 2 & 100 & 0 & 0 & 2 & 1.39 \\
\hline Total & 23 & 15.97 & 3 & 2.08 & 4 & 2.78 & 112 & 77.78 & 2 & 1.39 & 144 & 100 \\
\hline
\end{tabular}

In our study, we found that milky white per vaginal discharge was common in 139 cases i.e. $96.53 \%$. Candida was grown in culture in all cases with curdy white discharge i.e. $100 \%$. Trichomoniasis was grown in 1 case of greenish vaginal discharge. It is clear that very low no of women with discharge showed clinical evidence of classical type of vaginal discharge so as to diagnose Candida/ Trichomonas. Hence, we should be treating these women with symptoms empirically for Candida, Trichomonas and Bacterial vaginosis. Candida was grown in all cases with curdy white discharge, hence all cases presenting with curdy white discharge should be treated as Candidiasis (Table 3). 
In present study, we found that there was no specific growth in culture of vaginal swab and reported to be normal vaginal flora in $77.77 \%$ (112 of 144), while Kazmierczak W et al, found normal vaginal flora in $35 \%$ and Danielle et al, found normal vaginal flora in $50.5 \% .^{11,12}$ Hence we found that most common cause of vaginal discharge in pregnancy was due to physiological increase as the swab reports showed normal flora. While abnormal flora was found in $22.23 \%$ (32 of 144), among these Candidiasis was seen in $15.97 \%$ which is comparable with $11.8 \%$ found in study done by Danielle et al. It is also correlating well with study done by SM Ibrahim et al. ${ }^{13}$ Trichomoniasis was seen in $2.77 \%$ (4), Bacterial vaginosis seen in $2.08 \%$ (3) and mixed vaginitis (i.e. Candidiasis + Trichomoniasis) was seen in $0.69 \%$ (1). In our study, out of 280 subjects, 77 delivered in our institute till the results were compiled, out of 37 from cases group $25(67.56 \%)$ had FTND, $10(27.02 \%)$ had FTCS and $2(5.40 \%)$ delivered as PTND. While out of 38 from controls group $23(60.52 \%)$ had FTND and 15 $(39.47 \%)$ delivered by FTCS (Figure 7 ).

Table 3: Distribution of cases according to clinical looks of the per vaginal discharge.

\begin{tabular}{|c|c|c|c|c|c|c|c|c|c|c|c|c|}
\hline \multirow{2}{*}{$\begin{array}{l}\text { Colour of } \\
\text { discharge }\end{array}$} & \multicolumn{2}{|c|}{ Candidiasis } & \multicolumn{2}{|c|}{ Bacterial vaginosis } & \multicolumn{2}{|c|}{ Trichomoniasis } & \multicolumn{2}{|c|}{ No specific growth } & \multicolumn{2}{|c|}{ Others } & \multicolumn{2}{|c|}{ Total } \\
\hline & No & $\%$ & No & $\%$ & No & $\%$ & No & $\%$ & No & $\%$ & No & $\%$ \\
\hline Milky white & 21 & 15.11 & 3 & 2.16 & 3 & 2.16 & 110 & 79.14 & 2 & 1.44 & 139 & 96.53 \\
\hline Curdy white & 2 & 100 & 0 & 0 & 0 & 0 & 0 & 0 & 0 & 0 & 2 & 1.39 \\
\hline Greenish & 0 & 0 & 0 & 0 & 1 & 100 & 0 & 0 & 0 & 0 & 1 & 0.69 \\
\hline Altered brown & 0 & 0 & 0 & 0 & 0 & 0 & 2 & 100 & 0 & 0 & 2 & 1.39 \\
\hline Total & 23 & 15.97 & 3 & 2.08 & 4 & 2.78 & 112 & 77.78 & 2 & 1.39 & 144 & 100 \\
\hline
\end{tabular}

Figure 8 shows, that $4(10.26 \%)$ subjects from cases had preterm delivery and none from controls group had preterm delivery. Out of 4 subjects from cases, $2(5.12 \%)$ delivered as stillbirth because of severe oligohydraminos and severe intrauterine growth restriction. Lata I et al found that $53.65 \%$ of subjects with Bacterial vaginosis had preterm birth. ${ }^{14}$ In study done by Menard JP et al, found that there is statistical association between Bacterial vaginosis and preterm delivery. ${ }^{15}$ In the study done by Elizabeth et al found that in pregnant women in sub-Saharan Africa, most of whom were HIV-infected, neither Trichomoniasis nor its treatment appears to influence the risk of preterm birth or a low-birth-weight infant. This correlates well with our study. ${ }^{9}$

None of postpartum complication like puerperal sepsis, puerperal pyrexia, neonatal sepsis and adherent placenta was encountered in our study.

\section{Funding: No funding sources}

Conflict of interest: None declared

Ethical approval: The study was approved by the Institutional Ethics Committee

\section{REFERENCES}

1. Ibrahim SM, Mohammed B, Yahaya M, Audu BM, Ibrahim HA. Prevalence of vaginal candidiasis among pregnant women with abnormal vaginal discharge in Maiduguri. Nig J Med. 2013:138-142.

2. Demba E, Morison L, Schim van der Loeff $M$. Bacterial vaginosis, vaginal flora patterns and vaginal hygiene practices in patients presenting with vaginal discharge syndrome in The Gambia, West Africa. BMC Infect Dis. 2005;5:12.
3. Sherrard J, Donders G, White D, Jensen JS. European (IUSTI/WHO) guideline on the management of vaginal discharge, 2011. Int J STD AIDS. 2011;22(8):421-9.

4. Purwar M, Ughade S, Bhagat B, Agarwal V, Kulkarni H. Bacterial vaginosis in early pregnancy and adverse pregnancy outcome. J Obstet Gynaecol Res. 2001;27(4):175-81.

5. Helen M. Vaginal discharge- causes, diagnosis, and treatment. BMJ. 2004;328:1306.

6. McDonald HM, O'Loughlin JA, Jolley P, Vigneswaran R, Mc Donald PJ. Vaginal infection and preterm labour. $\mathrm{Br} \mathrm{J}$ Obstet Gynaecol. 1991;98:427-35.

7. Ibrahim SM, Mohammed B, Yahaya M, Audu BM, Ibrahim HA. Prevalence of vaginal candidiasis among pregnant women with abnormal vaginal discharge in Maiduguri. Gynecol Obstet Fertil. 2012;40(1):48-54.

8. Shrestha S, Tuladhar NR, Basnyat S, Acharya GP, Shrestha P, Kumar P. Prevalence of vaginitis among pregnant women attending Paropakar Maternity and Women's Hospital, Thapathali, Kathmandu, Nepal. Nepal Med Coll J. 2011;13(4):293-6.

9. Stringer E, Read JS, Hoffman I, Valentine M, Aboud $\mathrm{S}$, Goldenberg RL. Treatment of trichomoniasis in pregnancy in sub-Saharan Africa does not appear to be associated with low birth weight or preterm birth. S Afr Med J. 2010;100(1):58-64.

10. Romoren M, Velauthapillai M, Rahman M, Sundby J, Klouman E, Hjortdahl P. Trichomoniasis and bacterial vaginosis in pregnancy, inadequately managed with the syndromic approach, Bull World Health Org. 2007;85:297-304.

11. Kazmierczak W, Wnek M, Kaminski K: Frequency of vaginal infections in pregnant women in the 
Department of Perinatology and Gynaecology in Zabrze. Ginekol Pol. 2004;75(12):932-6.

12. Gondo DC, Duarte MT, Silva MG, Parada CM. Abnormal vaginal flora in low-risk pregnant women cared for by a public health service: prevalence and association with symptoms and findings from gynecological exams. Revista latino-americana de Enfermagem. 2010;18(5):919-27.

13. Ibrahim SM, Mohammed B, Yahaya M, Audu BM, Ibrahim HA. Prevalence of vaginal candidiasis among pregnant women with abnormal vaginal discharge in Maiduguri. Gynecol Obstet Fertil. 2012;40(1):48-54.

14. Lata I, Pradeep Y, Sujata AJ. Estimation of the incidence of bacterial vaginosis and other vaginal infections and its consequences on maternal/fetal outcome in pregnant women attending an antenatal clinic in a tertiary care hospital in North India. Indian J Comm Med. 2010;35(2):285-9.

15. Menard JP, Bretelle F. Bacterial vaginosis and preterm delivery. Gynecol Obstet Fertil. 2012;40(1):48-54.

Cite this article as: Khairnar VS, Waikar MR. Cytological and cultural evaluation of abnormal vaginal discharge in pregnancy and its co-relation with maternal and neonatal outcome. Int J Reprod Contracept Obstet Gynecol 2020;9:755-61. 